\title{
Alighting and Boarding Time Model of Passengers at a LRT Station in Kuala Lumpur
}

\author{
Peay San Hor $^{1}$, and Mohd Masirin Mohd Idrus ${ }^{1, *}$ \\ ${ }^{1}$ Faculty of Civil and Environmental Engineering, Universiti Tun Hussein Onn Malaysia, 86400 Batu \\ Pahat, Malaysia
}

\begin{abstract}
A research was conducted to study the factors affecting the alighting and boarding rate of passengers and establish a prediction model for alighting and boarding time of passengers for a passenger rail service in Malaysia. Data was collected at the KL Sentral LRT station during the morning and evening peak hours for a period of 5 working days. Results show that passenger behaviour, passenger volume, crowdedness in train and mixture of flow has significant effects on the alighting and boarding time though mixture of flow is not significant in the prediction model produced due to the passenger behaviour at the platform.
\end{abstract}

\section{Introduction}

As rail transportation is emerging to be the preferred choice for public transport in Kuala Lumpur, the quality of service provided by the rail operators is most important for the public. Apparently, dwell time is a key parameter of system performance, service reliability and quality in any mode of public transportation $[1,2]$. Over the years, more researches had been conducted about train dwell time. A review by Hor \& Mohd Masirin on past dwell time models revealed that the volume of alighting, boarding and standing throughpassengers had the most influence on dwell time models [3].

One of the earliest known train dwell time models was developed by Wirasinghe \& Szplett for Calgary LRT [4]. They produced three separate linear equations based on the percentage of boarders for a train. The authors found out that not only the volume of passengers boarding and alighting affected the dwell time, but the percentage of boarding and alighting passengers in the flow also had significant effect on dwell time, thus revealing the effect of a mixed flow.

This was soon followed by a non-linear model developed by Weston, which revealed that the dwell time increased with the volume of alighters and boarders at a declining rate, indicating a crowding effect [5]. In 2007, Harris \& Anderson applied the same model to estimate dwell times of metros and suburban railways around the world. They concluded that Weston's formula seemed to be valid around the world, and the overall structure of the approach appeared sound [6]. A non-linear dwell time model was also developed by Puong for the Massachusetts Bay Transport Authority (MBTA) in Boston revealed that the presence of standing through-passengers had an effect on the dwell time, specifically the

*Corresponding author: masiri@uthm.edu.my 
boarding time if there were more than 3 of standing through-passengers. Yet, Puong also found out that this had no or only a minor effect on the alighting process [1].

Lam, et al. developed a generalised linear model that included a fixed time for doors opening and closing, and the number of boarding and alighting passengers per train for the Hong Kong MTR system. They concluded that the dwell time did not increase infinitely with the increase of passengers due to the maximum allowable dwell time of trains being governed by the train headway [7].

Douglas established a model to predict train dwell time for RailCorp in Sydney [8]. Similar to Weston's model [5], he used a power function of 0.7 for both alighting and boarding because it gave a better fit than a linear function. Mixed flow of passengers and crowding effects caused by standing through-passengers in the model were included in the model by multiplying the number of standing passengers with the combined total of boarding and alighting passengers.

The studies mentioned above are related to dwell time, which include the time passengers alight and board the train, the time before the train doors are closed, and the time the train waits to depart with the doors closed [8]. The most critical part of the dwell time that relates to passenger movement is the alighting and boarding time but this varies from door to door due to the difference of volume of passengers alighting and boarding at each door and the crowdedness in the vehicle [2]. In Malaysia, there is little or even no published work about the alighting and boarding time for a door for an urban rail transit system. Therefore, this research aims to study the factors affecting the alighting and boarding time of passengers and establish a prediction model for alighting and boarding time of passengers for an urban rail transit system in Malaysia.

\section{Data collection}

The KL Sentral station, which is located on the Kelana Jaya LRT Line is a major interchange station that connects with the various rail routes in Kuala Lumpur. It has one of the highest passenger flows during the morning and evening peak hours. According to the statistics obtained from Public Land Transport Commission (SPAD) in May 2015, the arrival and departure ridership at KL Sentral exceeded 10,000 and 5,000 respectively in the morning peak hours from 07:00 to 09:00. In the evening peak hours (17:00 to 19:00), the arrival and departure ridership at KL Sentral were around 7,000 and 10,000 respectively. Therefore, it was chosen as the site for this study.

The movement of passengers alighting and boarding at one of the doors of each train was observed throughout the observation period. A total of 115 and 99 observations were recorded in the morning and evening peak respectively. The data collection was conducted from 07:30 to 08:30 during the morning peak and from 17:30 to 18:30 during the evening peak hours for a period of 5 working days at the KL Sentral LRT station.

Observation was conducted using a camera at the platform. The field data obtained from this observation were: a) Alighting passengers, b) Boarding passengers, c) Alighting and boarding times, and d) Crowdedness in the vehicle. The volume of alighting and boarding passengers and the time required for the whole process were obtained directly from the recordings whilst the crowdedness in the vehicle was estimated by observing the standing through-passengers in it.

On average, the dwell time for all trains in the morning and evening peak hours at KL Sentral was $50 \mathrm{~s}$ if there was no external interruption. The dwell times of trains at a station is fixed as the Kelana Jaya LRT Line is a fully automated train service. The dwell time of a train is taken to be from the moment it stopped at the platform to the moment it left the platform. This included the time required for passengers to alight and board the train, the 
time before the train doors were closed, and the time the train waits to depart with the doors closed [8].

For the purpose of this study, the time recorded during the observation is the alighting and boarding time for a selected door of each train, limited to clustered alighting and boarding only. In this study, a passenger is assumed to be part of a cluster if the time interval in the alighting and boarding process between his predecessor and himself is 3 seconds at the maximum. The time was measured from the moment the first person passed through the door (usually an alighter) till the moment the last person passed through it (usually a boarder).

To estimate the crowdedness of the train at each door, the fixed-route passenger load LOS [9] was used. Table 1 describes the standing passenger area for each LOS category, used mainly for vehicles designed to have most passengers standing. With the total standing area of the train at each door calculated using the measurements provided by the operator, the passenger load LOS at each door was estimated.

Table 1. Fixed-route passenger load LOS [9].

\begin{tabular}{|c|c|c|}
\hline LOS & Standing passenger area $\left(\mathbf{m}^{\mathbf{2}} \mathbf{p a s s}\right)$ & Standing passenger(s) per each $\mathbf{~ m}^{\mathbf{2}}\left(\mathbf{p a s s} / \mathbf{m}^{\mathbf{2}}\right)$ \\
\hline A & $>1.00$ & $<1.00$ \\
\hline B & $0.76-1.00$ & $1.32-1.00$ \\
\hline C & $0.51-0.75$ & $1.33-1.99$ \\
\hline D & $0.36-0.50$ & $2.00-2.85$ \\
\hline E & $0.20-0.35$ & $2.86-5.00$ \\
\hline F & $<0.20$ & $>5.00$ \\
\hline
\end{tabular}

\section{Results and discussion}

\subsection{Passenger behaviour}

From the observation conducted at the platform, it was noticed that there were more boarding passengers in the morning peak whilst more alighting passengers were sighted in the evening peak. This had an effect on the movement of passengers at the platform.

In the morning peak, where there were more boarding passengers, the passengers waiting for the train's arrival queued up in two separate lines at each door. This created a narrow channel in between the two lines, allowing the alighting passengers to enter the platform without being obstructed when they alighted, as can be seen in Fig. 1. Most of the time, the boarding passengers observed would allow all alighting passengers to alight first before they started boarding, except for a few instances where passengers began to board when they noticed that there was enough space in the train for them to move in.

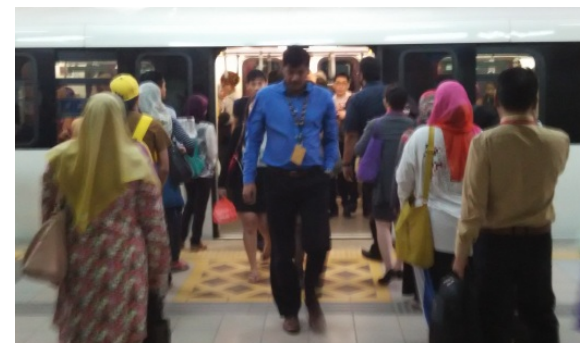

Fig.1. Passengers queuing prior to boarding 
In the evening peak, where there were more alighting passengers than boarding passengers, most of the boarding passengers queued in two separate lines at each door, as those observed in the morning, albeit shorter ones due to the lesser number of passengers. There were some instances where the boarding passengers did not form a queue and were standing in the keep-out zone, as shown in Fig. 2. This interrupted the flow of the alighting passengers, thus increasing the time required for alighting and boarding.

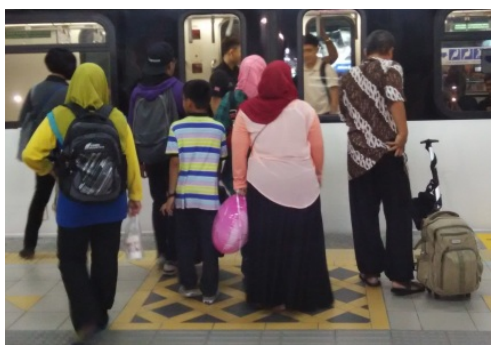

Fig. 2. Passengers waiting at keep-out zone

\subsection{Passenger volume}

The time used for alighting and boarding was measured for a selected door of each train. Fig. 3 shows that the increase in volume of passengers had increased the time required for alighting and boarding. Yet, it was observed that the volume of passengers and time required for boarding and alighting did not increase infinitely, but was bound by the capacity of the train and the dwell time of the train at the platform. Most of the observations show that the time required for alighting and boarding was below $30 \mathrm{~s}$, except for two observations which had an alighting and boarding time of $31 \mathrm{~s}$ and $37 \mathrm{~s}$ respectively. In terms of the volume of alighting and boarding passengers, a maximum of 51 passengers was recorded during the observation period.

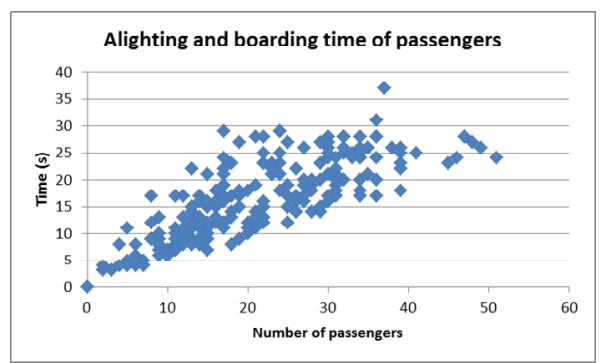

Fig. 3. Relationship between alighting and boarding time of passengers with the passenger volume

\subsection{Train crowdedness}

Crowdedness in the train was observed and analysed to study its effect upon passenger flow rate. The train crowdedness in this study is defined by the level of service (LOS) in the vehicle for a selected door observed.

As can be seen from Fig.4, the crowdedness of a train increased from LOS "C" to LOS "F", it was found that the passenger flow rate decreased significantly from a mean of 1.37 to $0.52 \mathrm{pass} / \mathrm{s}$. This is a reduction of more than $60 \%$ as compared to LOS "A", " $\mathrm{B}$ " and "C". Similarly, the range of the passenger flow rate also became smaller as the train became more crowded. When the number of standing through-passengers increases in the train, the 
amount of space available in the train reduces (refer to Table 1). This also means that the space available for the passengers to move when alighting and boarding the train is limited and causes the passenger flow rate to decrease significantly.

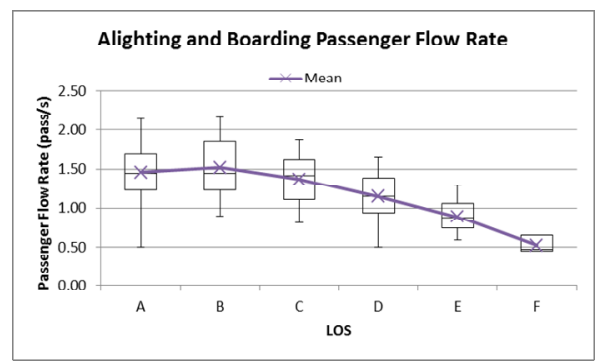

Fig. 4. Relationship between alighting and boarding passenger flow rate with LOS

\subsection{Mixture of flow}

Mixture of flow in the passenger flow is described as the difference between the number of alighters and boarders at a door of a train. Referring to Fig. 5, the overall passenger flow rate is lowest when the number of alighters and boarders are similar (high mixture of alighters and boarders). In contrast, the overall passenger flow rate is highest when there is a low mixture of alighters and boarders i.e. consisting mostly alighters or boarders only.

When there is a high mixture of alighting and boarding passengers, passengers are bound to "collide" with each other more, thus reducing the rate of alighting and boarding. Besides, passengers usually move in groups with a specific motivation: alighting or boarding. Thus, passengers with different motivations have an effect on the alighting and boarding rate [10].

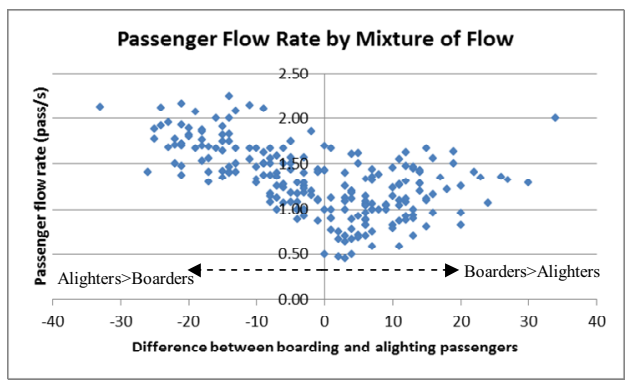

Fig. 5. Passenger flow rate by mixture of flow

\subsection{Model}

Using the regression analysis, a non-linear model to predict alighting and boarding time was produced. Initial variables included in the analysis were number of alighters, number of boarders, LOS in the train and percentage of alighters and boarders. The regression analysis removed variables that were not significant and as a result, Equation (1) was produced.

$$
\text { Time }=1.127 A^{0.7}+1.937 B^{0.7}+B \times C r
$$

with $A=$ number of alighters, $B=$ number of boarders, $C r=$ crowdedness index based on the LOS in the train (refer to Table 2). 
Table 2. Crowdedness index

\begin{tabular}{|c|c|}
\hline LOS & Cr \\
\hline A, B, C & 0 \\
\hline D & 0.122 \\
\hline E & 0.372 \\
\hline F & 0.790 \\
\hline
\end{tabular}

This model does not include a constant like many other dwell time models $[1,4,5,7$, $8]$ as this is an alighting and boarding time model. It does not take into consideration the dispatching time and unused time because they are independent of the passenger movement. Thus, this model considers only the time affected by the movement of passengers, which is the alighting and boarding time.

Based on the model produced, it is estimated that the time a passenger requires for boarding is more than that of alighting. Though this is in contrast to the models by Lam, et al. [7] and Douglas [8], this finding is similar to that of Puong's [1], who also found that boarding requires a longer time than alighting. This difference is acceptable because the behaviour of passengers at these stations studied were different.

If passengers at the platform stand in the keep-out zone, they would become a resistance to the alighting passengers, thus significantly increasing the time required to alight the train. In this study, it was observed that passengers at the platform had queued up and did not stand in the keep-out zone at most times. This allowed passengers to alight the train without obstruction and resistance. A power function of 0.7 was adapted from the model by Douglas [8] and this produced a slight improvement as compared to a linear function for both alighting and boarding times.

This model also reveals that when the LOS in the train is in the categories of A, B or C, it does not have any effect on the boarding time. But when the crowdedness in the train increases beyond LOS $\mathrm{C}$, this would result in the increase of the boarding time, thus increasing the overall alighting and boarding time. It is also noted that the crowdedness in the train has no or very minimal effect on the alighting time, similar to the finding by Puong [1].

In the analysis, the variable for mixed flow effect is found to be insignificant and thus removed from the model. This could be due to the reason that the observation was conducted during the peak hours, where most boarding passengers had queued up and did not obstruct the passengers who alighted from the train. Most of the boarding passengers were also found to practice the alight first board later system. This eliminates the effect of mixed flow and thus found to be not significant in the model produced.

\section{Conclusion}

Dwell time at station is a key indicator of system performance, service reliability and quality for passenger rail services $[1,2]$. Among the components of the dwell time, the alighting and boarding time is most related to the passenger movement at a platform. From this study at the KL Sentral LRT station, passenger behaviour has an effect on the passenger flow rate, with non-queuing passengers at the platform and those standing in the keep-out zone reducing the passenger flow rate. The increase in the passenger volume also increases the alighting and boarding time, though not infinitely as it is bound by the train capacity and the dwell time of the train at the platform. Crowdedness in the train reduces the passenger flow rate significantly as it increased from LOS "C" to LOS "F". Yet it has no effect when the LOS is LOS " $\mathrm{A}$ " to LOS " $\mathrm{C}$ ". In the event of a mixed flow, the alighting and boarding rates of passengers are lowest when there is a high mixture of alighters and boarders. The prediction model to estimate the alighting and boarding time of passengers 
produced using the regression analysis is significant with the inclusion of volume passengers and the LOS as variables. The effect of crowdedness is accounted for in this model but is not so for the effect of mixed flow. This is due to the passenger behaviour at the platform. Further study with different conditions i.e. during non-peak hours and other stations is recommended to further investigate the effects of the factors mentioned in this paper.

This paper was sponsored by the Office for Research, Innovation, Commercialization and Consultancy Management (ORICC), UTHM.

\section{References}

[1] A. Puong, Dwell time model and analysis for the MBTA red line, Massachusetts Inst. Technol. Res. Memo, 1-10 (2000)

[2] W. Chu, X. Zhang, J. Chen, and B. Xu, An ELM-Based approach for estimating train dwell time in urban rail traffic, Math. Probl. Eng., 2015, 1-9 (2015)

[3] P.S. Hor, and M.I. Mohd Masirin, Train dwell time models for rail passenger service, MATEC Web Conf., 47, 3005, (2016)

[4] D. Szplett, and S.C. Wirasinghe, An investigation of passenger interchange and train standing time at LRT stations: (i) Alighting, boarding and platform distribution of passengers, J. Adv. Transp., 18, 1-12 (1984)

[5] J.G. Weston, Train service model-technical guide, London Underground Operational Research Note 89/18, (1989)

[6] N.G. Harris, and R.J. Anderson, An international comparison of urban rail boarding and alighting rates, Proc. Inst. Mech. Eng. Part F J. Rail Rapid Transit, 221, 521-526 (2007)

[7] W.H.K. Lam, C.Y. Cheung, and Y.F. Poon, A study of train dwelling time at the hong kong mass transit railway system, J. Adv. Transp., 32, 285-295 (1998)

[8] N. Douglas, Modelling Train and Passenger Capacity, Sydney, (2012)

[9] TCRP, Report 100: Transit Capacity and Quality of Service Manual, Washington, (2003)

[10] Q. Zhang, B. Han, and D. Li, Modeling and simulation of passenger alighting and boarding movement in Beijing metro stations, Transp. Res. Part C Emerg. Technol., 16, 635-649 (2008) 